\title{
O sofrer da classe trabalhadora e seus processos críticos de adoecimento
}

\section{The suffering of the working class and its critical processes of illness}

\author{
Andreza Oliveira da Silva*, Luther King Andrade de Santana
}

Como citar esse artigo. SILVA, A. O; SANTANA, L. K. A. O sofrer da classe trabalhadora e seus processos críticos de adoecimento. Mosaico - Revista Multidisciplinar de Humanidades, Vassouras, v. 12, n. 3, p. xx-xx, set./ dez. 2021.

Nota da Editora. Os artigos publicados na Revista Mosaico são de responsabilidade de seus autores. As informações neles contidas, bem como as opiniões emitidas, não representam pontos de vista da Universidade de Vassouras ou de suas Revistas.

\begin{abstract}
Resumo
O modo de acumulação capitalista se fundamenta na exploração da classe trabalhadora e consequentemente em seu adoecimento psíquico. O presente artigo tem como finalidade levantar reflexões do processo saúde-doença a partir da conceituação normal/ patológico, em contraste ao modelo biomédico convencional, demonstrando a totalidade desse processo e focando não na nosologia dos sintomas, mas sim, em suas causas. A pesquisa, tem como diretiva para o aprofundamento desta discussão a alienação do trabalho. O artigo tem como base teórica a Psicologia Histórico-Cultural e o Materialismo Histórico Dialético com caráter qualitativo em revisão literária, levantando a discussão sobre a Saúde Mental a partir de uma perspectiva desnaturalizante com o aprofundamento das determinações e dos condicionamentos do adoecimento psíquico da classe trabalhadora. Desenvolvendo no caminho desse estudo a importância de se considerar a categoria da alienação da atividade como o ponto de partida e o ponto central no desenvolvimento do psiquismo e de seu adoecimento, de modo a compreendê-lo em seu sentido social e histórico. Para que pudéssemos ter uma maior compreensão sobre a realidade frente as suas particularidades, refletimos sobre a dialética singular-particular-universal auxiliando na desnaturalização e na desindividualização dos adoecimentos psíquicos demonstrando que o sofrimento e a mortificação se intensifica e modifica a partir das transformações da sociedade.

Palavras-chave: Saúde Mental; Alienação; Dialética singular-particular-universal; Saúde-doença; Histórico-cultural; Materialismo Dialético.
\end{abstract}

\begin{abstract}
The capitalist accumulation mode is based on the exploitation of the working class and consequently on their mental illness. This article aims to raise reflections on the health-disease process from the normal/pathological conceptualization, in contrast to the conventional biomedical model, demonstrating the totality of this process and focusing not on the nosology of symptoms, but on their causes. The research has as a directive to deepen this discussion the alienation of work. The article has as its theoretical basis the Historical-Cultural Psychology and the Dialectical Historical Materialism with a qualitative character in a literary review, raising the discussion on Mental Health from a denaturalizing perspective with the deepening of the determinations and conditionings of the psychological illness of the working class. Developing in the way of this study the importance of considering the category of activity alienation as the starting point and the central point in the development of the psyche and its illness, in order to understand it in its social and historical sense. So that we could have a better understanding of reality in face of its particularities, we reflected on the singular-particular-universal dialectic, helping to denaturalize and de-individualize psychological illnesses, demonstrating that suffering and mortification intensifies and changes from the transformations of society.

Keywords: Mental Health; Alienation; Singular-particular-universal dialectics; Health-disease; Historical-cultural; Dialectical Materialism.
\end{abstract}

\section{Introdução}

O sofrimento psíquico vem atingindo generalizadamente a classe trabalhadora, determinado pelos modos de vida característicos da atual fase da acumulação capitalista, tendo a medicalização contribuindo para a consolidação de uma concepção naturalizante da vida social, perpetuando uma culpabilização do sujeito e dessa forma ocultando as suas implicações e dificultando uma análise que desnude as reais determinações do adoecimento. O artigo buscou entender os processos do sofrimento psíquico, partindo de uma análise na qual, a produção de conhecimento e práticas cientificas atualmente estão hegemonizadas por concepções biológicas, sendo pautadas em uma lógica produtivista do capital. Para que isso fosse possível, retomamos as contribuições da Psicologia Histórico-Cultural e o Método Materialista HistóricoDialético, enquanto revisão bibliográfica possuindo como perspectiva o desenvolvimento da autonomia e emancipação humana, contrapondo às perspectivas naturalizantes.

Com a impossibilidade da prática, levantamos questões sobre o sofrimento psíquico que perpassa de forma coletiva e singular, afim de uma produção de caminhos possíveis para lidar com o processo desses indivíduos da classe trabalhadora que já se encontram adoecidos. Com isso, o trabalho teve o compromisso

Afiliação dos autores:

Universidade de Vassouras, Vassouras, RJ, Brasil

*Email de correspondência: : ddoliveiraa98@gmail.com 
de discorrer sobre uma produção cientifica teórica que contribua para uma possível transformação radical social, superando o capitalismo e construindo uma sociedade sem classes, baseadas no desenvolvimento do gênero humano, ou seja, na universalidade dos indivíduos. Se faz explicito, o dilema desse artigo que, apesar de ter pretensão de contribuir significativamente, conhece de antemão seus limites e as lacunas que, com certeza, deixará abertas. Utilizamos a expressão: sofrimento psíquico, para nos referir aos termos dos transtornos de humor, compreendendo que se difere ao da Psiquiatria, como uma alternativa crítica aos conceitos de 'doença mental'. Foi abordado de forma breve o início da participação da Psicologia na Saúde Mental e sobre o processo saúde-doença enquanto um processo social normal/patológico, e para estarmos aprofundando os determinismos do adoecimento psíquico na classe trabalhadora, vamos discorrer sobre a alienação do trabalho e sobre a dialética singular-particular-universal auxiliando na desnaturalização e na desindividualização do sofrimento psíquico.

\section{O processo saúde-doença a partir do normal/patológico}

Em consonância com Almeida, Bellenzani e Schüli (2020), o crescimento dos movimentos sociais na década de 80 junto à promulgação da Constituição da República Federativa do Brasil de 1988, adquiriu-se abertura para a discussão sobre a necessidade de equipes multiprofissionais atuando em políticas públicas. Com a ratificação da Lei Orgânica de Saúde e o Sistema Único de Saúde (SUS) ter a sua estruturação, gradativamente aconteceu a contratação de psicólogas (os) nas Políticas de Saúde. E o aumento, com caráter significativo, se dá a partir da lei 10.216, de 6 de abril de 2001, o que em tese, estaria dispondo sobre a proteção e os direitos das pessoas portadoras de transtornos mentais e redirecionando o modelo assistencial em Saúde Mental, colocando os profissionais de psicologia como equipe mínima nos Centros de Atenção Psicossocial, sendo mais recentemente inserido nos Núcleos de Apoio à Saúde da Família (NASF).

E somente a partir da necessidade da atuação dos psicólogos dentro das políticas de saúde, transformouse a atividade, ou seja, a sua forma de atuação que antes majoritariamente era realizada autonomamente em atendimento clínico. "A Saúde Pública despontava como o setor público com a maior concentração de profissionais. Em números absolutos, a pesquisa dava conta de 29. 212 psicólogas (os) atuando no SUS." (ALMEIDA et al., p. 230. 2020) No entanto, mesmo tendo grande atuação nos setores públicos, o que se dava predominantemente enquanto modelo clinicoliberal, contribuindo para o despreparo dos profissionais diante do sofrimento psíquico da classe trabalhadora, e reforçando o modelo naturalizante que impõem o sofrimento psíquico descolado de sua historicidade, sendo este modelo o biomédico convencional, um parâmetro que ainda é utilizado na compreensão e tratamento das patologias, bem como para definir o que é saúde e em contraste o que é doença. "Na sociedade capitalista, por exemplo, o conceito de doença explícita está centrado na biologia individual, fato que lhe retira o caráter social. " (Laurell, 1982, p. 9)

De acordo com Laurell (1982), o processo saúdedoença adquire historicidade pela sua determinação social,masnão se esgotando somente nesta determinação, pois o próprio processo biológico humano é social, pelo "fato de que não é possível determinar qual é a duração normal do ciclo vital, por ser ele diverso em diferentes épocas." (LAURELL, 1982, p. 8)

A doença não pode ser compreendida apenas pelas expressões nosológicas, pois a mesma não é descolada do indivíduo, logo, é o sofrimento do tal que estará estabelecendo o estado da doença, assim como, as características do morrer daquele grupo no qual o indivíduo está inserido. "A natureza social da doença não se verifica no caso clínico, mas no modo característico de adoecer e morrer nos grupos humanos. " (LAURELL, 1982, p. 3). Apesar do modelo médico convencional, compreender a saúde como um estado de plenitude, não há limites precisos entre o estado da normalidade e da patologia, mas uma relação recíproca de ambas. Além disso, os mesmos fatores que asseguram o bem-estar e a vida dos sujeitos (água, moradia, ar, trabalho, tecnologia etc.) também podem se transformar em fatores patológicos, o que em muitas teorias que se pontuem sobre o estilo de vida the transfere a responsabilidade por meio de condutas, a prerrogativa da suposta escolha individual. Não há um modelo unicausal sobre o adoecimento, demarcados, portanto, não somente por aquilo que é físico, mas em suas determinações biológicas, psicológicas históricos e sociais. Logo, enquanto compreensão social, a doença "refere-se à incapacidade de trabalhar, o que a coloca em relação com a economia e eventualmente com a criação da mais-valia e possibilidade de acumulação capitalista" (Laurell, 1982 p.9). Superar a visão monista e a lógica biopsicossocial, que fragmenta o sujeito e estar compreendendo a historicidade acerca do conceito 'doença' retira o reducionismo fatorial, que the foi imposto e apreende uma concepção generalizada do seu processo saúde-doença.

O estado de saúde e de sofrimento é compreendido a partir da dimensão do singular, no entanto, se dá de forma generalizada compreendendo qual posição o ser ocupa em sua dimensão social. De forma breve podemos pensar no processo saúde-doença como: "[...] o conjunto de relações e variáveis que produz e condiciona o estado de saúde e doença de uma 
população, sendo que essa determinação se modifica de acordo com o processo histórico da humanidade. " (BASTOS, 2013, p. 10) O processo saúde-doença, não é formado por estados isolados:

"[...] para as suas condições concretas têm como base a posição socioeconômica e cultural do indivíduo como classe social, e atravessando esse processo e intensificando as desigualdades sociais, temos o gênero e a etnia" (MARTIN, 2020, p. 92)

É importante ressaltar que assim como Laurell (1982) mostra, não é na compreensão sintomatológica das patologias de forma individualizada que será compreendido seu caráter social e histórico, mas a partir dos seus perfis patológicos, nos quais os grupos apresentam, considerando o tipo de patologia e a frequência que determinado grupo apresenta no qual, em um dado momento, as classes mostrarão condições diferentes de saúde. A partir desta historicidade podemos compreender que atualmente a humanidade encontrou formas de lidar com esse sofrimento psíquico cristalizando os corpos adoecidos como objeto privativo das Ciências da Saúde, principalmente da Medicina Clínica. Além disso, a partir da patologização e da medicalização compulsória dos trabalhadores adoecidos, se dá a dominação desses trabalhadores exigindo sujeitos cada vez mais produtivos, os tornando objetos de controle a partir de intervenções, quando é imposto que os fenômenos diversos que causam sofrimento são sempre do caráter patológico, se adquire uma posição reguladora do que énormal ou patológico. Énotório como os cuidados restauradores individualizados da medicina convencional não colaboram com a saúde coletiva, e que a promoção da saúde muitas vezes justifica as ações normativas e higienista dessa concepção organicista, e que as práticas psicológicas existentes atualmente não se fazem suficiente para as demandas da saúde mental, pois não se concretiza o impedimento dos processos críticos que agem na produção do sofrimento psíquico.

"Se desta maneira a "normalidade" biológica define-se em
função do social, também a "anormalidade" o faz. [...] O
caráter simultaneamente social e biológico do processo saúde-
doença não é contraditório, porém unicamente assinala que
pode ser analisado com metodologia social e biológica, na
realidade, comoumprocessoúnico."(LAURELL, 1982,p.12)

Quanto a medicina convencional, não se faz objeto do texto ou da psicologia marxista negar a existência de estruturas biológicas presentes no adoecimento, mas compreender que este biológico é determinado pelo social de forma hierárquica e que esta visão ideologizante, não se acessa sua totalidade sobre o sofrimento psíquico, nos reportando apenas a uma parte da problemática e "o caráter parcial, deste modo, não permite avançar o conhecimento, senão em algumas áreas, deixando outras ocultas. " (Laurell, 1982, p. 10). É importante frisar que o termo, saúde- doença não se esgota somente pela ótica do normal/ patológico, no entanto, dentro do que nos propomos a discutir escolhemos essa direção para fazer nossos apontamentos. Portanto, tivemos como questão: quais são as reais determinações, e não os determinantes fatoriais para o processo saúde-doença que afetam a saúde do trabalhador enquanto ser histórico e social? E com isso, queremos contribuir, de alguma forma, para a potencialização e construção de uma Saúde Coletiva.

\section{A alienação da atividade}

A Psicologia Histórico-Cultural surge no início do século XX na União Soviética, no contexto pósRevolução Russa com Lev Semionovich Vigotski, tendo Baruch de Spinoza como um dos grandes influenciadores de suas obras. Seus parceiros foram Alexis Leontiev e Alexander Lúria. A Psicologia Histórico-Cultural aborda seus temas a partir do Método Materialista Histórico-Dialético, de Karl Marx que se baseou nos princípios da lógica dialética de Hegel, pressupondo uma compreensão dos fenômenos em sua processualidade e totalidade ao desnudamento de sua concretude, tendo a dialética fundamentada no movimento, sendo provisórios, necessitando ter uma história no passado e devendo ter outra no futuro, concebendo um começo e tendo que ter um final. Uma teoria que contribui com a classe trabalhadora tomando parte do projeto de emancipação humana. Foi realizada uma revisão de literatura utilizando autores da abordagem histórico-cultural para que tivéssemos um auxílio na compreensão do sofrimento psíquico a partir da alienação da atividade.

Segundo Lavoura (2018), o materialismo trouxe recursos para se compreender o homem dentro da totalidade histórica, permitindo trabalhar com a historicidade dos fenômenos, por isso, contrapõese à sua naturalização, conseguindo demonstrar de forma científica a partir da dialética que, o modo de produção capitalista é um modo de produção particular, especificamente definido pelo desenvolvimento histórico. Sendo, portanto, histórico e transitório.

Partiremos do pressuposto de que, a atividade é inerente ao ser, sendo esta produzida de forma coletiva. Além de ser a mediação central que possibilita o desenvolvimento pleno e que responde às necessidades dos indivíduos e a transformação humana. Referiremos aqui ao fato de que o homem, enquanto um ser social constituído pelo trabalho, ou seja, pela atividade, apropria-se das leis essenciais da natureza e transforma em objeto e condição de sua vida, tendo a necessidade do homem não mais somente dirigido pelas leis gerais da sua espécie, mas também em seu caráter social e histórico. 
Conforme Silva (2019), para que possamos compreender o sofrimento psíquico, a alienação da atividade (trabalho) foi o ponto de partida desta investigação, sendo esta alienação um processo constitutivo e inicial desintegrador do psiquismo. A desintegração não desconsidera os fatores biológicos, mas associa este processo diretamente à atividade. Ao pensarmos na alienação da atividade precisamos estudar as condições de sua execução, a relação desta atividade profissional com as condições sociais determinadas e, a partir disso, também surge a necessidade de pensar estes mecanismos que consolidam a alienação para 0 indivíduo e no indivíduo.

Segundo Moraes (2009), o ser humano domina a natureza em suas relações sociais, faz dela sua matériaprima e a partir da mesma desenvolve os meios para sua existência, sendo essa relação sempre mediada pelo trabalho. No entanto, no capitalismo, se faz daquilo que era parte do seu corpo inorgânico e sua capacidade produtiva externalizada (atividade) um produto, em um processo de estranhamento, tornando-o como propriedade privada, ou seja, mercadoria. O que antes era mediado pelo trabalho, não se faz mais. A relação entre indivíduo e natureza possui, pela lógica do capital, uma mediação de segunda ordem: seu trabalho, o sujeito e a propriedade privada. Já que não pode ser apropriado de forma imediata, mas somente por seu salário. É a partir da atividade laboral que o trabalhador consegue sobreviver (salário) e é decorrente a essas condições desgastantes e degradantes que o indivíduo adoece. E quando há o adoecimento e o rendimento se compromete, o trabalhador é responsabilizado por 'não' estar se adaptando a essa realidade. Entendemos que, o adoecimento aparece como uma forma de resistência passiva, quase como uma denúncia das contradições do capitalismo que se reinventa reiteradamente perpetuando a exploração, demonstrado por vincular a uns supostos comportamentos estereotipados. Assim como demonstra Silva (2019 p.105): “[...] o que evidencia, no mínimo, a necessidade de o indivíduo se esquivar por completo ou de essas serem radicalmente modificadas. "Com as contribuições de Silva (2019) nos questionamos: com quais mecanismos o capital afeta o singular em sua forma mais íntima? Afetar de forma direta a vida cotidiana, a esfera mais propensa a alienação. $\mathrm{Na}$ vida cotidiana o singular, de certa forma, se faz isolado de sua universalidade. Aquilo que se vive diariamente. Quando as características cotidianas se cristalizam e se constituem baseados na divisão de classes, o indivíduo é impedido de compreender a sua realidade para além do fenômeno perceptível sobre si mesmo, sobre sua atividade e suas determinações.

"Podemos dizer, então, que alienação é o processo no qual as atividades humanas começam a se realizar como se fossem autônomas ou independentes dos homens e passam a dirigir e comandar a vida dos homens sem que estes possam controlá-las." (MARTIN, 2020, p. 93.)

A organização do trabalho se deu a partir de três concepções, os modelos taylorista, fordista e toyotista, que apesar de suas distinções, exige da classe trabalhadora responder às demandas solicitadas estabelecendo a forma, quando e o quanto devem estar produzindo. Conforme as contribuições de Ribeiro (2015); Martin (2020) o cerne do capitalismo se dá em sua própria manutenção e expansão da mais-valia; para que isso seja possível, o capital vai instaurando estratégias para a sua continuidade. Os modelos, taylorista/fordista são símbolos de rigidez, no fordismo com a intensificação da parcelarização das tarefas e a divisão do trabalho, para que se diminuísse o tempo ocioso (por meio de dispositivos mecânicos encadeadores de tarefas sucessivas) intensificaram a degradação física e mental da classe trabalhadora pela expansão de jornada e condições insalubres de trabalho.

$\mathrm{Na}$ atual revolução tecnológica do capital, o toyotismo - como símbolo de flexibilização, na medida que, se afasta dos outros modelos, prioriza maximizar os benefícios para o capital minimizando os custos com os trabalhadores a partir da intensificação do trabalho, provoca sofrimento e adoecimento exigindo que a classe trabalhadora se mantenha em uma performance adequada de trabalho, estarem à altura de suas exigências - formação, informação, nível de conhecimento, experiência. Posto isso, compreendemos que o adoecimento da classe trabalhadora e a alienação de sua atividade se dá desde os primórdios do capitalismo e suas reestruturações.

As reestruturações do capital, sendo estas independentes da nossa vontade, constroem relações que correspondem há uma etapa histórica, determinada pelo desenvolvimento das forças produtivas materiais, se estabelecendo a partir da exploração do trabalho, consequentemente a precarização do mesmo e a fragmentação dos operários, se estruturando uma individualização do sujeito, gerando uma competitividade proposital. Pois é nesta totalidade que se "forma a estrutura econômica da sociedade, a base real sobre a qual se ergue uma superestrutura jurídica e política, e à qual correspondem determinadas formas da consciência social." (MARX, 1859, n.p.)

Deve-se também pontuar a necessidade de controle sobre o tempo dos trabalhadores, o condicionamento do corpo e da vida, onde as pessoas se veem em um mundo em que a velocidade é praticamente um valor. Portanto, o modo de produção é dado em sua totalidade, dependendo da forma que nos relacionamos que nos faz produzir e reproduzir suas determinações. Logo, dentro desta historicidade encontramos os trabalhadores tendo que subordinar, as suas próprias necessidades fisiológicas. 
A partir das contribuições de Moraes (2009) a mão-de-obra do proletariado deve ser "livre", pois assim seria "livremente vendida" ao seu empregador. $\mathrm{O}$ mundo exterior não é mais um objeto pertencente à sua atividade, dessa forma, o trabalhador se torna servo do seu objeto, que antes era condição inseparável de sua atividade e "o auge dessa servidão é que somente como trabalhador ele [pode] se manter como sujeito físico e apenas como sujeito físico ele é trabalhador" (MARX, 2008b, p. 82 apud Moraes, 2009, p. 37) o que torna concreta a sua alienação na vivência proletária, a impossibilidade da apropriação singular de forma direta dos objetos pertencentes à sua atividade e das construções do gênero humano.

A subjetividade, para Ribeiro (2015), que emerge das relações de trabalho, quanto à participação do trabalhador no processo produtivo, se faz de forma inautêntica e estranha em relação ao que se produz e para quem se produz. E a alienação pode ser compreendida com esse estranhamento entre o processo do trabalho, ao produto de sua atividade e ao indivíduo qual produz, podendo ser manifesta no contraste entre o indivíduo existente ao indivíduo idealizado, ou seja, quem eu sou? E quem eu gostaria de ser? Tendo o trabalho assalariado como apenas uma forma de satisfação frente as suas necessidades. O que neste caso pode-se gerar autodepreciação ou um não respeito a si mesmo. A exacerbação do individualismo advinda da competitividade, reproduz a concepção do sucesso e do fracasso, isolando o indivíduo de seus laços sociais de forma meritocrática, responsabilizando somente o trabalhador, retirando a determinação sofrida pela reestruturação dos modos de produção. Ao mesmo tempo emqueos sintomasquesão apresentados ecompreendidos como algo unicausal e de apenas uma via resolutiva: de forma individual. Dificultando a compreensão dos trabalhadores enquanto classe e retirando sua noção de pertencimento, consequentemente enfraquecendo sua luta e aprofundando a classe trabalhadora em uma alienação ainda mais profunda.

Retornando a análise de Silva (2019) a alienação possui como uma das suas formas, o fetichismo. Todo fetichismo é uma alienação e ele se dá como a forma mais predominante de alienação no capitalismo. Outra forma de alienação se dá, quando há em si mesmo o estranhamento frente às suas capacidades e habilidades. E assim,

"[...] a relação entre as mercadorias se manifesta de forma misteriosa, impossibilitando ao trabalhador compreender essas relações que o afetam diretamente, tanto de forma objetiva (por não conseguir atender as necessidades criadas nessa relação e em outras) quanto subjetiva (a não satisfação das diferentes necessidades o mortifica, faz com que se sinta cansado física e mentalmente, como Marx já havia descrito em 1844). ” (SILVA, 2019, p. 105)
Esta relação misteriosa, chamamos de fetichismo, ocorrendo somente quando há produção de mercadorias, sendo ele justamente a conversão das relações sociais (entre pessoas) em relações de uso e troca (entre coisas) mediada por uma produção de valor. No processo de gerar valor, atribuir o aumento da mais-valia e o expropriar do trabalhador, se dá o fetichismo. "No fetichismo, o processo de coisificação entre o homem e o produto de seu trabalho e entre os próprios homens, os levam a coisificarem suas relações com a humanidade, com as características do gênero humano. " (SILVA, 2019, p. 106).

A partir da coisificação do homem, a força de trabalho se torna objeto, o trabalho que antes pertencia a ele, não mais lhe pertence, mas sim, a outra pessoa. Perdendo a finalidade de transformação, mas tendo como obrigatoriedade a construção de novas mercadorias que valorizem o capital. A mercadoria passa a dominar o homem. Como consequência disso, o ter é mais importante que o ser devido à expropriação do produto (natureza) de sua atividade, a única forma de resgate a esse mesmo produto, seria através do dinheiro adquirindo posição central na sociedade e sendo, agora, elemento indissociável aos homens enquanto meio de subsistência. O salário agora passa a ser significado e objeto de sua atividade, diferente do significado primário daquilo que de fato se faz com a sua transformação, ou seja, o seu trabalho de forma concreta.

\section{Dialética singular-particular-universal}

Ao discorrer sobre a alienação do trabalho e do trabalhador, sendo esta alienação ponto central para o adoecimento, é importante destacarmos como princípio metodológico a dialética singular-particular-universal que contribui a uma legítima e verdadeira aproximação e compreensão da realidade. De acordo com Oliveira (2001) a universalidade dos processos históricos humanos se concretiza na singularidades dos processos de adoecimentopsíquicomediados pelas particularidades sociais, devendo as relações existentes ser explicitadas entre essas dimensões. O que infere a necessidade de observar as respectivas circunstâncias socioeconômicas nas quais ocorrem, para compreender e caracterizar em que direção às transformações históricas determinam a forma e o conteúdo dessa relação. O singular nos traz a percepção do imediato, ou seja, aquilo que se demonstra na aparência do fenômeno, e de forma imediata não obtemos um enfrentamento a realidade, senão pela compreensão de sua totalidade. Porém, no método materialista dialético, a singularidade não nos revela sua essencialidade de forma concreta. A singularidade, em si mesma, encontra-se ainda no plano da aparência do fenômeno e 
"É preciso, portanto, ultrapassar os limites dessas manifestações mais imediatas para conhecer quais são suas raízes processuais, não imediatamente perceptíveis, que formam a totalidade onde tais manifestações são produzidas. Dizendo de outra forma: é preciso compreender o processo ontológico da realidade humana e de como esse processo tem se efetivado, historicamente, dentro das relações sociais de produção. "(OLIVEIRA, 2001, p. 17)

Segundo Pasqualini (2015), é a análise do pseudoconcreto (empírico) que apreende a concreticidade do fenômeno. O que precisa ser compreendido neste momento é que, superar a aparência do fenômeno envolve desnudar quais são as mediações que determinam e constituem o singular, superando a pseudoconcreticidade - manifestação imediata/empírica - em direção à concreticidade do fenômeno estudado possuindo a necessidade de abstrair momentaneamente o fenômeno imediato e compreender as leis explicativas que regem não só esse fenômeno, mas sua totalidade. Quanto à universalidade (gênero humano) precisamos dizer que: o singular e o universal coexistem, não como pontos de vista, sendo estes polos opostos da unidade dialética, se articulando e se determinando de forma recíproca dando vida ao fenômeno.

Lavoura (2018) explicita que a universalidade se concretiza na singularidade, se integrando em uma mesma totalidade, mas se isoladamente o singular se dá meramente como aparência fenomênica e o "mero" universal é demasiadamente abstrato por não possuir mediações que os constituem, ao estarmos analisando esta totalidade devemos buscar as múltiplas determinações (particularidades).

Podemos observar com o que foi exposto até o presente momento que, entre singular e universal, existe uma tensão dialética, que compreenderemos como particularidade. A particularidade nos explicita os mecanismos atuantes no modo de ser da singularidade e da universalidade, ou seja, a particularidade se coloca como mediação carregando determinações ao singular e ao universal. Não há conhecimento do fenômeno sem a compreensão da particularidade.

"Tendo em vista o que aqui foi exposto, a questão
epistemológica da relação singular-particular-universal na
atuação do psicólogo terapeuta e pesquisador constitui-
se na relação entre a singularidade (o indivíduo) e a
universalidade (o gênero humano), a qual se concretiza
através das múltiplas mediações determinadas pelas relações
sociais específicas do contexto (a particularidade) em que
esse indivíduo está inserido" (OLIVEIRA, 2001, p. 20)

Trazendo a dialética singular-particularuniversal para a particularidade do sofrimento psíquico, afirmamos que as perejivânies ${ }^{1}$ de cada indivíduo são singulares, que este sofrimento restringirá os interesses e os modos de andar a vida. Desta forma, conforme Almeida, Bellenzani e Schüli (2020), a complexidade dos processos que operam na produção histórico-cultural das situações-problemas do singular (individuo) em sofrimento psíquico não se revela de forma direta e de fácil acesso ao pesquisador ou profissional de saúde.

Portanto, em um primeiro momento teremos acesso ao estado emocional do mesmo. E na medida em que seja aprofundada a compreensão da totalidade por meio da análise - abstração - teremos uma compreensão cada vez maior e mais simples do que, a priori, se apresentava de forma caótica. Este contato direto com a realidade nos permite duas coisas: o acesso a perejivânies da história expressadas na singularidade e o desnudamento da complexidade da vida em sua concretude. Com esses elementos expostos, passamos a compreender as condições e as mediações constituintes deste sofrimento psíquico nas mais variadas dimensões. "Sua inserção de classe, as condições gerais de vida, suas necessidades de consumo não satisfeitas, os limites impostos pelo sofrimento psíquico, os vínculos pessoais estabelecidos." (ALMEIDA; BELLENZANI; SCHÜLI, 2020 , p. 252). Deve-se considerar que o sofrimento psíquico se evidencia da totalidade (universalidade) a partir da identificação de uma demanda da saúde com sintomas de depressão, bipolaridade, esquizofrenia, alcoolismo etc.- logo, é a partir desta demanda que, estaremos compreendendo como o fenômeno a ser conhecido e a qual devemos estar atuando.

Chamamos de singular o que aparece enquanto manifestação imediata, o que pode ser contemplado de forma viva. O que trataríamos como indivíduo 'em sofrimento' representa essa singularidade - a partir de uma alteração patológica na personalidade, que será exigido do profissional de Saúde uma teorização maior para que se compreendam as determinações mais profundas ao fenômeno, identificando assim, os processos críticos e dessa forma seja formulado os meios de atuação.

Para Almeida (2018), é de grande importância a particularidade nesta análise, pois a partir da sua compreensão elucidamos os mecanismos que intervinham de forma determinante e decisivamente no modo de ser singular. Aparentemente, é na passagem do particular ao singular que se expressam as demandas sociossanitárias. Prosseguindo em uma análise do sofrimento psíquico, a particularidade se referiria aos padrões de desgastes e reprodução em suas relações sociais. Além de estereótipos de adaptação, pelos quais indivíduos singulares se fazem pertencentes aos grupos sociais.

\footnotetext{
"Conforme sua inserção nas relações sociais, os indivíduos estarão condicionados pelo pertencimento a uma determinada classe social, a uma dada atividade concreta, a uma certa condição de gênero e etnia etc. E cada um desses grupos sociais se constitui segundo determinados padrões que combinam desgaste e reprodução e estão sujeitos a processos críticos específicos, levando à constituição de "formas históricas específicas biopsíquicas
} 
humanas" (Almeida; Bellenzani; Schüli2020, p. 257)

De acordo com Almeida et al. (2020) quanto a análise da universalidade: as leis gerais que regem a totalidade. Ao que concerne ao sofrimento psíquico, seria o processo de organização e reprodução social como a divisão de classes, o fato dos indivíduos não obterem os meios de produção, a alienação, e de forma determinada a sua exploração, ou seja, a apropriação dos excedentes do trabalho dos trabalhadores pelos proprietários dos meios de produção. Gerando níveis crescentes de desigualdades, logo aqui estará sendo analisado dentro da dialética o universal sendo - o capitalismo - um sistema histórico de dominação que não há distribuição coletiva da produção do trabalho que favorece, a partir desse modo de vida, o adoecimento em forma de sofrimento psíquico.

Com tudo o que foi demonstrado ao longo do texto, a questão principal aqui para estarmos pensando no adoecimento da classe trabalhadora, é demonstrar que o sofrimento e a mortificação se intensifica e modifica a partir das transformações da sociedade e de suas particularidades. Além disso, devemos estar pautados em uma compreensão de que o capital busca incessantemente alternativas para retomar os níveis de acumulação mediante suas crises e reestruturação. $\mathrm{O}$ processo saúde-doença possui como base as questões socioeconômicas, culturais, políticas e das condições gerais da vida e suas particularidades associados diretamente ao acesso aos bens produzidos pela própria classe, o trabalho, seu acesso em serviços essenciais, a educação, sua organização social e econômica. Portanto, o sofrimento psíquico advém da tentativa de uma adaptação a uma normatividade ${ }^{2}$ que contrasta às demandas e os motivos do indivíduo.

\section{Conclusão}

No início da discussão foi abordado de forma breve, sobre como a compreensão biomédica convencional do processo saúde-doença é essencialmente biológica e incapaz de desnudar os seus nexos e sua complexidade de forma concreta, em contraste foi discutido o processo saúde-doença através da compreensão do que é normal/patológico. E que o desintegrador do psiquismo não exclui a existência de estruturas biológicas, mas, associa de forma direta a atividade. No entanto, o mesmo não se esgota somente nesta compreensão do normal/patológico, mas para os nossos fins específicos, apontamos sua constituição e determinação a partir dessa ótica.

O processo saúde-doença constituído e determinado pelo social tem por diretiva que a análise sobre os processos de saúde-doença não se devem ser feitos de forma individualizada, mas de forma coletiva distinguindo seu objeto de estudo - grupos, e quais são suas características gerais do adoecer e do morrer, para uma compreensão além do abstrato fatorial, a compreensão biopsicossocial do indivíduo, o fragmenta retirando a dialética deste processo e consequentemente a sua totalidade.

Além disso, foi explicitado que as terapêuticas centralizadas na medicalização destinadas para esses adoecimentos, advinda da medicina convencional provocam efeitos que geram a cronificação destes sofrimentos. A Psicologia Histórico-Cultural e o Materialismo Histórico-Dialético compreendem, portanto, que a produção do processo saúde-doença no sujeito se dá de modo integral, e que o contexto no qual está inserido impacta diretamente seu psiquismo e suas relações.

O adoecimento psíquico se dá desde os primórdios do capitalismo e de suas reestruturações, com a alienação da expropriação da atividade e o assalariamento da sua força de trabalho, compreendemos quais são os mecanismos que se demonstram naturalizados e como os mesmos se tornam alvos de alienação, retirando do sujeito o que em primeiro momento era parte de si.

As organizações de trabalho determinam os modos de adoecer e fragiliza o reconhecimento social e simbólico do processo de construção de identidades coletivas e individuais. O sofrimento psíquico, portanto, se manifesta de forma a denunciar as contradições do capitalismo que lhe impõem uma adequação pelos estereótipos de adaptação, às demandas impostas pelo capitalismo. Devemos buscar a consciência em relação à sua atividade, ou seja, o trabalho e sua inserção na sociedade, a partir da tomada de consciência s o indivíduo possui maiores possibilidades do autocontrole como também controle do mundo que o cerca. Terminando a discussão com as esferas da dialética singularparticular-universal ficam evidentes os interesses da classe dominante em subornar o desenvolvimento e a saúde em prol da exploração e do acúmulo de riquezas por uma minoria. Tal como foi possível compreender que, a determinação da exploração do trabalho implica no adoecimento da classe trabalhadora.

Temos um compromisso não só coma emancipação política, mas a emancipação humana enquanto sociedade, sistematizando e aprofundando conhecimentos sobre o adoecer da classe trabalhadora, ainda que o avanço das políticas públicas seja insuficiente frente aos processos críticos do adoecimento e que a possibilidade de ser amenizado esse sofrimento pelas ideologias dominantes, só são realizadas quando cria-se a necessidade para que a lógica de produção e o sistema do capital se mantenham em funcionamento, é imprescindível resistir. Com a compreensão da historicidade dos fenômenos em sua totalidade percebemos que eles se dão de forma social, histórica e transitória.

Justamente por compreender os processos 
críticos do adoecimento psíquico da classe trabalhadora é importante frisar que somente através da transformação radical social que impõem as condições que fundamentam essa opressão e determinações do sofrimento psíquico teremos uma modificação de forma concreta e objetiva para os trabalhadores, ou seja, somente a partir da luta coletiva e do sindicalismo destes, enquanto organização, será concretizada a superação do capitalismo e a transformação dos modos de produção e por consequência sua organização de trabalho.

\section{Notas}

1. Perejivânie, conceito de Vigotski que aparece pela primeira vez em "A tragédia de Hamlet, príncipe da Dinamarca". Possui relação com as emoções e as vivências que impactam o indivíduo e seu desenvolvimento, transformando e modificando sua relação com a realidade experienciada. Tal processo explica porque o ambiente social não se dá de maneira absoluta, mas possui sentidos diferentes nas singularidades. Assim como para Spinoza, na relação com o mundo afetamos e somos afetados. ANDRADE, L. R. M. de; CAMPOS, H. R. Perejivânie: . Obutchénie. Revista de Didática e Psicologia Pedagógica, n. 3, v. 2, p. 1-17, 2019. Disponível em: https://doi. org/10.14393/OBv3n2.a2019-51558. Acesso: 21 set. 2021.

2. Conceito de Canguilhem que discorre sobre o processo saúde-doença a partir do normal/patológico. Não é patológico (ou deixa de sê-lo) quando o indivíduo pode controlar sua conduta de forma consciente, intencional. SEGURO, Vladimir. O que é uma normatividade vital? Saúde e doença de Georges Canguilhem. Sci. viga., São Paulo, v. 9, n. 1, p.1-17, 27 de novembro de 2011. Disponível em: http://www.scielo.br/scielo.php?script=sci arttext \&pid=S167831662011000100002\&lng=en\&nrm=iso. Acesso em: $\overline{11}$ maio 2021. https://doi.org/10.1590/S1678-31662011000100002

\section{Referências}

ALMEIDA, Melissa Rodrigues de. A formação social dos transtornos de humor. Tese (Doutorado em Medicina) - Universidade Estadual Paulista “Júlio de Mesquita Filho", Faculdade de Medicina de Botucatu. Botucatu, 417p., 2018. Disponível em: https://repositorio.unesp.br/handle/11449/153333 Acesso em: 28. Fev. 2021

ALMEIDA, M. R. et al. A dialética singular-particular-universal do sofrimento psíquico: articulações entre a psicologia histórico-cultural e a teoria da determinação social do processo saúde-doença, p.229-272. In: TULESKI, Silvana Calvo; FRANCO, Adriana de Fátima; CALVE, Tiago Morales (Org.). Materialismo histórico-dialético e psicologia históricocultural: expressões da luta de classes no interior do capitalismo. Paranavaí: EduFatecie, 2020

Andrade, L. R. M. de, \& Campos, H. R. (2019). Perejivânie: . Obutchénie. Revista De Didática E Psicologia Pedagógica, 3(2), 1-17. https://doi. org/10.14393/OBv3n2.a2019-51558. Disponível em: http://www.seer.ufu.br/ index.php/Obutchenie/article/view/51558/27349. Acesso em: 21. Set. 2021.

BASTOS, Jota. Determinação social do processo saúde-doença: conceito para uma nova prática em saúde. Revista COES em movimento, p. 1-22. disponível em: https://www.denem.org.br/cartilhas/Cartilha\% $\% 20$ -\%20Determina\%C3\%A7\%C3\%A3o\%20social\%20do\%20processo $\% 20$ sa $\%$ C3 $\%$ BAde $\% 20$ doen $\%$ C3\%A7a $\% 20-\% 20$ COES.pdf. Acesso: 21 set. 2021

CAPUCCI, Raquel Rodrigues; SILVA, Daniele Nunes Henrique. "Ser ou não ser": a perejivanie do ator nos estudos de LS Vigotski. Estud. Psicol. (Campinas), Campinas, v. 35, n. 4, pág. 351-362, dezembro de 2018. Disponível em http://www.scielo.br/scielo.php?script=sci arttext\&pid=S0103-166X2018000400351\&lng=en\&nrm=iso. Acesso em: 07 abr. 2021.

CORDEIRO, Mariana Prioli. Psicologias sociais cientificista e crítica: um debate que continua. Psicol. Cienc. prof., Brasília, v. 33, n. 3, pág. 716729, 2013. Disponível em http://www.scielo.br/scielo.php?script=sci arttext\&pid=S1414-98932013000300015\&lng=en\&nrm=iso. Acesso em: $1 \overline{1}$ mar. 2021.

COSTA, Eduardo Moura da. Materialismo histórico-dialético como fundamento da psicologia histórico-cultural: método e metodologia de pesquisa. Psicol. Esc. Educ., Maringá, v. 20, n. 2, p. 393-396, Aug. 2016. Disponível em: http://www.scielo.br/scielo.php?script=sci arttext\&pid=S1413-85572016000200393\&lng $=$ en\&nrm=iso. Accesso em: 25 mar. 2021.

LAVOURA, Thiago Nicola. A Dialética do Singular-Universal-Particular e o Método da Pedagogia Histórico-Crítica. Estudos sobre Educação, Presidente Prudente-SP, v. 29, n. 2, p.4-18, mai. /ago., 2018. ISSN: 22360441. Disponível em: https://revista.fct.unesp.br/index.php/Nuances/article/ view/6044. Acesso em: 02. Mar. 2021.

LAURELL, A. C. "La salud-enfermedad como proceso social". Revista Latinoamericana de Salud, México, 2, 1982, p. 7-25. Trad. E. D. Nunes. Disponível em: https://unasus2.moodle.ufsc.br/pluginfile.php/6126/mod resource/content/1/Conteudo on-line 2403/un01/pdf/Artigo_A_SAUDEDOENCA.pdf. Acesso em: 20 mar. $20 \overline{2} 1$.

MARX, Karl, Para a crítica da economia política. Primeira Edição: No livro: Zur Kritik der Politischen Oekonomie von Karl Marx. Erstes Heft, Berlin 1859. Obras Escolhidas em três tomos, Editorial"Avante!” Tradução: José BARATA-MOURA (Publicado segundo o texto do livro. Traduzido do alemão). Março 2007. p.271. Disponível em: https://www.marxists.org/ portugues/marx/1859/01/prefacio.htm Acesso em: 18. Set. 2021.

MARTIN, Sueli T. F. Trabalho Alienado, Capitalismo e a Saúde do Trabalhador Enquanto Processo Histórico e Social, p.89-108. In: TULESKI, Silvana Calvo; FRANCO, Adriana de Fátima; CALVE, Tiago Morales (Org.). Materialismo histórico-dialético e psicologia histórico-cultural: expressões da luta de classes no interior do capitalismo. Paranavaí: EduFatecie, 2020.

MARTINS, Lígia Márcia. A natureza histórico-social da personalidade. Cafajeste. CEDES, Campinas, v. 24, n. 62, pág. 82-99, abril de 2004. Disponível em: http://www.scielo.br/scielo.php?script=sci arttext\&pid=S0101-32622004000100006\&lng=en\&nrm=iso. Acesso em: 20 mar. 2021.

MORAES, Renata. J. S. Trabalho Alienado e Adoecimento Psíquico da Classe Trabalhadora: Contribuições à Luz da Psicologia Histórico-Cultural. 2009. 81f. Monografia. (Graduação). Departamento de Psicologia. UFPR. PR. Curitiba, 3 de dezembro de 2009.Disponível em: http://www.nupemarx. ufpr.br/Trabalhos/Monografias/monografia_renata_moraes.pdf. Acesso em: 10 mar.2021.

OLIVEIRA, Beth. A Dialética do Singular-Particular-Universal, p. 1-21 In: ABRANTES, Angelo Antonio; SILVA, Nilma Renildes da; MARTINS, Sueli Terezinha Ferreira. Método Histórico-Social na Psicologia Social. Petrópolis: Vozes, 2001. ISBN 85,326,3129-0.

PASQUALINI, J. C. Dialética Singular-Particular-Universal e sua Expressão na Pedagogia Histórico-Crítica: Primeiras Aproximações. Rev. SimbioLogias, v. 12, n. 17, 2020. Disponível em: https://www.ibb.unesp.br/Home/ ensino/departamentos/educacao/dialetica_singular-particular-universal_e sua expressao na_pedagogia.pdf. Acesso em: 07. Mar. 2021.

PASQUALINI, Juliana Campregher; MARTINS, Lígia Márcia. Dialética Singular-Particular-Universal: Implicações do Método Materialista Dialético para a Psicologia. Psicol. Soc., Belo Horizonte, v. 27, n. 2, p. 362-371, agosto de 2015. Disponível em http://www.scielo.br/scielo.php?script=sci arttext\&pid=S0102-71822015000200362\&lng=en\&nrm=iso. Acesso em: $1 \overline{1}$ mar. 2021. https://doi.org/10.1590/1807-03102015v27n2p362

RIBEIRO, Andressa de Freitas. Taylorismo, fordismo e toyotismo. Lutas Sociais, São Paulo, v.19, n³5,p.73-jul/dez.2015 Disponível em: https:// revistas.pucsp.br/index.php/ls/article/viewFile/26678/pdf. Acesso: 03 . Março. 2021.

SILVA, Flávia Gonçalves. A Alienação e a Patopsicologia como Categorias para a Compreensão do Adoecimento Psíquico Ocupacional. p. 103-114. In: TULESKI, Silvana Calvo; FRANCO, Adriana de Fátima (org.). O processo de desenvolvimento normal e anormal para a psicologia histórico-cultural: estudos contemporâneos. Maringá :Eduem, Ebook. 2019. Disponível em: http://old.periodicos.uem.br/ eduem/novapagina/?q=node/721 Acesso em: 09. Mar. 2021

SEGURO, Vladimir. O que é uma normatividade vital? Saúde e doença de Georges Canguilhem. Sci. viga., São Paulo, v. 9, n. 1, p.1-17, 27 de novembro de 2011. Disponível em: http://www.scielo.br/scielo.php?script=sci arttext \&pid=S167831662011000100002\&lng=en\&nrm=iso. Acesso em: $\overline{11}$ maio 2021. https://doi.org/10.1590/S1678-31662011000100002

TULESKI, Silvana Calvo. A Unidade do Psiquismo Humano para 
Vigotski e a Desagregação desta na Esquizofrenia. Psic.: Teor. e Pesq.,

Brasília , v. 35, e35424, Epub, 02 de dezembro de 2019. Disponível em: $\quad$ http://www.scielo.br/scielo.php?script=sci arttext\&pid=S0102-

37722019000100524\&lng=en\&nrm=iso. Accesso em: 11 Mar. 2021.

VIAPIANA, Vitória Nassar. A depressão na sociedade contemporânea: contribuições da teoria da determinação social do processo saúde-doença. Dissertação, Universidade Federal do Paraná, Curitiba, 2017. 178p..

Disponível em: https://acervodigital.ufpr.br/handle/1884/49331. Acesso em: 28. Fev. 2021. 